American Journal of Pharmacology and Toxicology 6 (3): 80-83, 2011

ISSN 1557-4962

(C) 2011 Science Publications

\title{
Slow Fungal Hydrolysis of Complex Sugar is Responsible for the Use of Sugar as Vehicle for Antifungal Drugs
}

\author{
${ }^{1}$ Nedosa Ikenna Valentine, ${ }^{2}$ Utoh-Nedosa Uchechukwu Anastasia, \\ ${ }^{3}$ Dan Danjuma, ${ }^{4}$ Onyedibe Kenneth and ${ }^{5}$ Sylvester Chukwukere \\ ${ }^{1}$ Department of Industrial Microbiology, Faculty of Science, \\ Federal University of Technology, Owerri, Imo State, Nigeria \\ ${ }^{2}$ Department of Pharmacology and Toxicology, \\ Faculty of Pharmaceutical Sciences, Nnamdi Azikiwe University, \\ Awka, PMB 5025, Awka, Anambra State, Nigeria \\ ${ }^{3}$ Department of Biochemistry, College of animal Health and Production, \\ Veterinary Research Institute, Vom, Plateau State, Nigeria \\ ${ }^{4}$ Department of Medical Microbiology, \\ Jos University Teaching Hospital, Jos, Plateau State, Nigeria \\ ${ }^{5}$ Diagnostics and Microbiology Laboratory, \\ Veterinary Research Institute, Vom, Plateau State, Nigeria
}

\begin{abstract}
Problem statement: Aspergillus niger strain (UUF 9202) significantly reduced the dormancy period and boosted aggregate germination time in seeds of Tetrapleura tetraptera by $42 \%$ in 32 days and produced a net reduction in mean germination time of the seeds to 12 days. A structurefungitoxicity relationship study of a series of isoflavonoids against Aspergillus niger and Cladosporium cucumerinum showed that a high level of lipophilicity and the presence of at least one phenolic function appear important for isoflavonoid fungitoxicity. Amphotericin $\mathrm{B}$, the best drug for deep or systemic infections is not active orally and as such is administered intra venously. The two intravenous formulations of amphotericin B include a complex of amphotericin B and Deoxycholate (DOC) and a Small Unilamella Vesicle containing (SUV) amphotericin B combined with $350 \mathrm{mg}$ of lipid in Soy lecithin; cholesterol and distearoylphosphatidylglycerol. Approach: A study found that dispersion in concentrated sugar solution provided a better vehicle for marked antifungal effect of Eucalyptus camaldensis than distilled water eventhough both the sugar solution extract and the distilled water extract had equal antifungal activity against clinical dermatophyte isolates of Microsporium gypseum and Trichophyton mentagrophytes $(\mathrm{P}=0.05)$. This study hydrolysed cassava starch, through the action of isolated alpha and beta-amylase enzymes on the one hand and through the action of Aspergillus niger fungal cells on the other; to find out why lipids and complex carbohydrates are the best vehicles of antifungal drugs and plant extracts. Results: The results of the study showed that $\alpha$ and $\beta$ amylase enzymes hydrolysed gelatinized starch in $1 \mathrm{~h}$ while Aspergillus niger hydrolysed the same quantity of gelatinized starch in $72 \mathrm{~h}$ under the same conditions. These results show that Aspergillus niger hydrolyses complex carbohydrates (high calorie foods) very slowly. The findings of the study suggest that complex carbohydrates like the starch in this study; the concentrated sugar solution in the Eucalyptus camaldensis study and the soy lipid/cholesterol in amphotericin B SUV formulation; present antifungal drugs effectively for antifungal activity on fungal infections because fungal organisms take days to slowly hydrolyse such complex carbohydrate foods (high calorie foods) as has been demonstrated by the 3 days hydrolysis of gelatinized (cooked) starch by Aspergillus Niger. It is this slow hydrolysis of the cellulose of the seed coat of Tetrap [eura tetraptera by Aspergillus niger (strain UUF 9202) that significantly reduced the dormancy period; bosted aggregate germination time of the seeds by $42 \%$ in 32 days and reduced the mean germination of the seeds to 12 days in a situation in which seeds soaked in pre-sterised Aspergillus niger spore suspension at $30^{\circ} \mathrm{C}$ gave zero germination. The findings of this study suggest that Aspergillus niger hydrolysis of starch at room temperature engages the Aspergillus niger cells fully for a long period of three days which constitutes feeding on the starch for its own energy generation. While the Aspergillus niger cells are engaged in the 3-day hydrolysis of a complex carbohydrate vehicle of an antifungal drug, the drug simultaneously
\end{abstract}

Corresponding Author: Nedosa Ikenna Valentine Faculty of Industrial Microbiology, Federal University of Technology, Owerri, Imo State, Nigeria 
engages in the elimination of the fungi. Conclusion: These findings therefore suggest that slow speed hydrolysis of complex carbohydrates in the host body for its own food is a major mechanism of Aspergillus niger (and other fungi) infectivity of their human and other hosts. Reduction of complex carbohydrate intake is thus hereby identified as an important factor in the control of fungal infections. Also for antifungal herbal extracts and other antifungal drugs that do not need to be presented to infective fungi by complex carbohydrates, their activity will be enhanced by concurrent reduction of complex carbohydrate intake which will thus result in eradication of the fungal infection in question.

Key words: Antifungal activity, antifungal drugs, complex carbohydrates, fungal infection, Aspergillus niger, antifungal herbal, major mechanism, antifungal drug, calorie foods

\section{INTRODUCTION}

Amphoterisin B is the drug of choice for the treatment of the following systemic and topical mycoses:

- Immunosuppressed invasive Aspergillosis

- Nonimmunosuppressed invasive Aspergilosis

- Rapidly progressive or central Nervous System Blastomycosis

- rapidly progressive Coccidiodomycosis

- Meninggeal Blastomycosis

- Non-AIDs Cryptococcosis

- Initial AIDs Cryptococcosis

- Rapidly progressing or CNS Histoplasmosis

- Mucurmycoses

- Extracutaneous Sporotrichosis

- Cutaneous Candidiasis

The mechanism of the antifungal activity of amphotericin B has been proposed to be due (at least in part) to its bindind to a sterol moiety (primarily ergosterol) in the membrane of sensitive fungi to form pores or channels in these membranes which allow leakage of a variety of small molecules from these membranes (Bernkop-Schnurch, 2005). The involvement of additional mechanisms of action of amphoterisin B was noted (Bernkop-Schnurch, 2005). This study aimed at making some imputes into the mechanisms of action of antifungal drugs.

The study involved experimental hydrolytic breakdown of gelatinized by $\alpha$ and $\beta$-amylase enzymes on the one hand and Aspergillus niger culture on the other with a view of comparing the results of the two experiments.

\section{MATERIALS AND METHODS}

Cassava starch was prepared from grated wholesome mature cassava roots under aseptic conditions. Water was expressed from the starch and the solid starch was stored in a freezer at $0^{\circ} \mathrm{C}$.

All materials used for conducting all the experiments were handled under aseptic conditions.
Alpha and beta amylase enzymes: Pure alpha $[\alpha]$ amylase $\{120$ L NOVO NORDISK) and Beta [ $\beta]$ amylase enzymes were obtained from Jos International Breweries (JIB) plc [Production Unit], Jos, Plateau State, Nigeria and maintained at temperatures below $10^{\circ} \mathrm{C}$ during the period of the research work.

Aspergilus niger whole cells: Pure cultures of Aspergillus niger were obtained from the diagnostic and microbiology laboratories of the National Veterinary Research Institute, Vom, Plateau State, Nigeria.

Preparation of the starch solution for the two experiments and their control: Fifty grams of the cassava starch prepared for the experiments was placed in a clean beaker to which $100 \mathrm{~mL}$ of distilled water was added and stirred in to form slurry.

In a second step, $850 \mathrm{~mL}$ of gently boiling water were added to the slurry as it was simultaneously stirred. This action gelatinized the starch. The gelatinized starch was made up to 1 liter with distilled water to give $50 \mathrm{~g} \mathrm{~L}^{-1}$ gelatinized starch solution.

Experiment a-treatment of the gelatinised starch with $\alpha$ and $\beta$ amylase enzymes: Two hundred milliliters $(200 \mathrm{~mL})$ of the $50 \mathrm{~g} \mathrm{~L}^{-1}$ gelatinized starch was put in a $500 \mathrm{~mL}$ beaker and stood in a water bath whose temperature was kept at $70^{\circ} \mathrm{C}$ by a thermostat. The $\mathrm{pH}$ of the solution in the beaker was between 5.5 and 7.5 which were considered favourable for the experiment.

About $1 \mathrm{~mL}$ of $\alpha$ amylase enzyme obtained for the experiment, was added to the gelatinized starch solution after which the starch solution sample in the beaker was left to interact with it for $30 \mathrm{~min}$.

At the end of the interaction with $\alpha$-amylase, the temperature of the starch sample was lowered from 70$60^{\circ} \mathrm{C}$ and $1 \mathrm{~mL}$ of $\beta$-amylase enzyme was added to the sample starch solution to interact with it for $30 \mathrm{~min}$. The solution that resulted from the reaction of $\alpha$ and $\beta$ amylases with the gelatinized starch was tested for the presence of starch. 
Experiment B (control experiment 1): Two hundred milliliters $(200 \mathrm{~mL})$ of the $50 \mathrm{~g} \mathrm{~L}^{-1}$ gelatinized starch was put in a $500 \mathrm{~mL}$ beaker and stood in a water bath whose temperature was kept at $70^{\circ} \mathrm{C}$ by a thermostat. The $\mathrm{pH}$ of the solution in the beaker was between 5.5 and 7.5 which were considered favourable for the experiment.

Nothing was added to the gelatinized starch solution but it was left to stand for $30 \mathrm{~min}$,

At the end of the $30 \mathrm{~min}$, the temperature of the starch sample was lowered from $70-60^{\circ} \mathrm{C}$ and nothing was added to the sample starch solution but it was left for $30 \mathrm{~min}$. The solution that resulted at the end of this experiment was tested for the presence of starch.

Experiment $\mathrm{C}$, treatment of the gelatinised starch with aspergilus niger whole cells: Two hundred milliliters $(200 \mathrm{~mL})$ of the $50 \mathrm{~g} \mathrm{~L}^{-1}$ gelatinized starch was put in a $500 \mathrm{~mL}$ conical flask and $1 \%$ innoculum of a $48 \mathrm{~h}$ culture of Aspergillus niger in peptone water was added to the solution while agitating the solution.

The flask was sealed properly with cotton wool to prevent contamination and left at room temperature for 72 h. At the end of $72 \mathrm{~h}$, the broth was centrifuged at 3000 rpm for 20 min according to the method of (BernkopSchnurch, 2005) to remove the micro-organisms. The supernatant was tested for the presence of starch.

Experiment D, Control experiment 2- Treatment of the gelatinised starch without Aspergillus niger whole cells: two hundred milliliters $(200 \mathrm{~mL})$ of the $50 \mathrm{~g}$ liter $^{1}$ gelatinized starch was put in a $500 \mathrm{~mL}$ conical flask and nothing was added to the solution while agitating the solution.

The flask was sealed properly with cotton wool to prevent contamination and left at room temperature for $72 \mathrm{~h}$. At the end of $72 \mathrm{~h}$, the broth was centrifuged at $3000 \mathrm{rpm}$ for $20 \mathrm{~min}$ according to the method of Abouzied and Reddy. The supernatant was tested for the presence of starch.

Test for starch: Two to 4 drops of the solution to be tested for starch was put in a petri dish. Two drops of iodine were dropped on the solution on the petri dish. The appearance of a blue-black color on contact of reagent iodine with the sample indicates the presence of starch in the sample.

\section{RESULTS}

The resultant solution at the end of experiment A tested negative for the presence of starch showing that $\alpha$ and $\beta$-amylase treatments of the gelatinized starch hydrolyzed the $200 \mathrm{~mL}$ of the $50 \mathrm{~g} \mathrm{~L}^{-1}$ gelatinized starch completely into simple sugars in $1 \mathrm{~h}$.

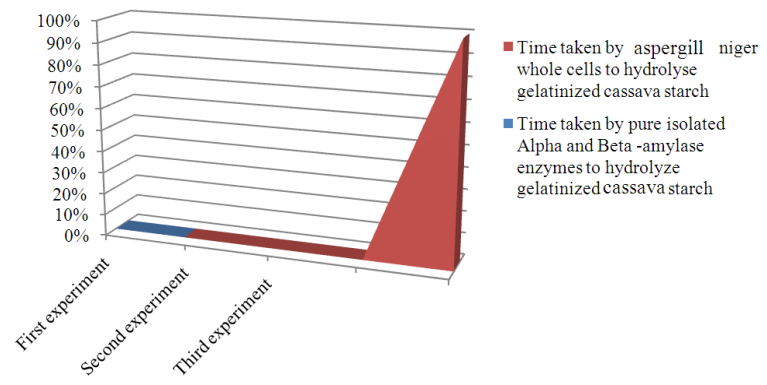

Fig. 1: A graphic representation of the $71 \mathrm{~h}$ difference between the speed of $\alpha$ and $\beta$-amylase-hydrolysis of gelatinized cassava starch and the speed of Aspergillus niger-hydrolysis of the same quantity of cassava starch

There was no starch hydrolysis in experiment B as its resultant solution tested positive for starch showing that the starch hydrolysis in experiment $\mathrm{A}$ was due to the action of $\alpha$ and $\beta$-amylases on the gelatinized starch.

The resultant solution at the end of experiment $\mathrm{C}$ tested negative for the presence of starch showing that Aspergillus niger treatment of the gelatinized starch hydrolyzed the $200 \mathrm{~mL}$ of the $50 \mathrm{~g} \mathrm{~L}^{-1}$ gelatinized starch completely into simple sugars in $72 \mathrm{~h}$.

The resultant solution at the end of experiment $\mathrm{D}$ tested positive for the presence of starch showing that Aspergillus niger treatment of the gelatinized starch caused the hydrolysis of the $200 \mathrm{~mL}$ of the $50 \mathrm{~g} \mathrm{~L}^{-1}$ gelatinized starch completely into simple sugars in $72 \mathrm{~h}$.

A comparism of the rate or speed of cassava starch hydrolysis of isolated $\alpha$ and $\beta$-amylase enzymes with that of the fungus Aspergillus niger is shown in Fig. 1.

\section{DISCUSSION}

Alpha amylase acted at random locations along the starch chain to break it domn to less omplex sugars like maltose and glucose (Licy et al., 2010). On the other hand, beta amylase started from the second alpha-1, 4glucosidic bond and broke down the starch molecule cleaving off two glucose molecules at a time (Gasco, 2007). Thus $\alpha$-amylase liquefied the starch (Borges et al., 2008) while $\beta$-amylase saccharifyed the starch speed of three days or $72 \mathrm{~h}$.

\section{CONCLUSION}

These results suggest that Aspergillus niger hydrolysis of starch at room temperature engages the Aspergillus niger cells fully for a long period of three 
days. While Aspergillus niger cells are engaged in the 3-day hydrolysis of a complex carbohydrate vehicle of an antifungal drug, the drug will simultaneously en gage in the elimination of the fungi. These findings therefore suggest that slow speed hydrolysis of complex carbohydrates in the host body is a major mechanism of Aspergillus niger (and other fungi) infectivity of its human and other hosts. Reduction of complex carbohydrate intake is thus hereby identified as an important factor in the control of fungal infections. Some plant food products have antioxidant and antimicrobial properties (Mohan et al., 2008; Atai et al., 2009; Thomas and Kropp, 2011; Baez-Flores et al., 2008) thus eating such foods will increase the body's resistance to fungal infections and enhance the effectiveness of antifungal agents.

\section{REFERENCES}

Atai, Z., M. Atapour and M. Mohseni, 2009. Inhibitory effect of ginger extract on Candida albicans. Am. J. Applied Sci., 6: 1067-1069. DOI: 10.3844/ajassp.2009.1067.1069

Baez-Flores, M.E., R. Troncoso-Rojas and M.E. Tiznado-Hernandez, 2008. Biochemical and genetic responses of fungi to the toxic effect of synthetic and natural fungicides. Am. J. Agric. Biol. Sci., 3: 348-357. DOI: 10.3844/ajabssp.2008.348.357
Bernkop-Schnurch, A., 2005. Thiomers: A new generation of mucoadhesive polymers. Adv. Drug Deliv. Rev., 57: 1569-1582. DOI: 10.1016/j.addr.2005.07.002

Borges, O., A. Cordeiro-da-Silva, J. Tavarus, N. Santarem and A.D. Sousa et al., 2008. Immune response by nasal delivery of hepatitis $\mathrm{B}$ surface antigen and codelivery of a $\mathrm{CpG}$ ODN in alginate coated chitosan nanoparticles. Eur. J. Pharm. Biopharm., 69: 405-416. DOI: 10.1016/j.ejpb.2008.01.019

Gasco, M.R., 2007. Lipid nanoparticles: Perspectives and challenges. Adv. Drug Deliv. Rev., 59: 377378. PMID: 17582649

Licy, C.D.. K. Premalatha, A. Shirwaikar and A. Shirwaikar, 2010. Formulation and evaluation of a novel needle-free hepatitis B surface antigen delivery system. Am. Med. J., 1: 88-96. DOI: 10.3844/amjsp.2009.88.96

Mohan, S., A.B. Abdul, S.I.A. Wahab, A.S. Al-Zubairi and M.M. Elhassan et al., 2008. Antibacterial and antioxidant activities of Typhonium Flagelliforme (Lodd.) blume tuber. Am. J. Biochem. Biotechnol., 4: 402-407. DOI: 10.3844/ajbbsp.2008.402.407

Thomas, E. and B.R. Kropp, 2011. Suppression of salicylic acid-mediated plant defense responses during initial infection of Dyer's woad by Puccinia thlaspeos. Am. J. Agric. Biol. Sci., 6: 307-316. DOI: 10.3844/ajabssp.2011.307.316 